\title{
Urban Myths and the Mis-use of Data that Underpin them 1
}

\author{
David Satterthwaite²
}

March 2010

\begin{abstract}
This paper describes the gaps and limitations in the data available on urban populations for many low- and middle-income nations and how this limits the accuracy of international comparisons - for instance of levels of urbanization and of the size of city populations. It also discusses how the lack of attention to data limitations has led to many myths and misconceptions in regard to growth rates for city populations and for nations' levels of urbanization. It ends with some comments on how data limitations distort urban policies.
\end{abstract}

Keywords: urbanization, city populations, censuses

JEL classification: O18, C80, F59

Copyright (C) UNU-WIDER 2010

1 This is extracted from a longer, more detailed report: Satterthwaite (2007). However, this chapter drew from a later source for urban statistics; unless otherwise stated, these are drawn from UN (2008).

2 International Institute for Environment and Development (IIED), email: david.satterthwaite@iied.org

This study has been prepared within the UNU-WIDER project on Beyond the Tipping Point: Development in an Urban World directed by Jo Beall, Basudeb Guha-Khasnobis, and Ravi Kanbur.

UNU-WIDER gratefully acknowledges the financial contributions to the research programme by the governments of Denmark (Royal Ministry of Foreign Affairs), Finland (Ministry for Foreign Affairs), Sweden (Swedish International Development Cooperation Agency-Sida) and the United Kingdom (Department for International Development). 
The World Institute for Development Economics Research (WIDER) was established by the United Nations University (UNU) as its first research and training centre and started work in Helsinki, Finland in 1985. The Institute undertakes applied research and policy analysis on structural changes affecting the developing and transitional economies, provides a forum for the advocacy of policies leading to robust, equitable and environmentally sustainable growth, and promotes capacity strengthening and training in the field of economic and social policy making. Work is carried out by staff researchers and visiting scholars in Helsinki and through networks of collaborating scholars and institutions around the world.

www.wider.unu.edu

publications@wider.unu.edu

UNU World Institute for Development Economics Research (UNU-WIDER)

Katajanokanlaituri 6 B, 00160 Helsinki, Finland

Typescript prepared by Anne Ruohonen at UNU-WIDER

The views expressed in this publication are those of the author(s). Publication does not imply endorsement by the Institute or the United Nations University, nor by the programme/project sponsors, of any of the views expressed. 


\section{Introduction}

Comparisons between nations have long had a central place in discussions of economic and social development and, more recently, of environmental performance. Because cities or urban systems have such importance for economic growth, social development, governance, and environmental performance, so the comparisons between nations' urban populations or city populations, or their population growth rates have been common. There is also an interest in assessing progress in development among urban and rural populations, and this includes levels of poverty and provision for services (as in assessing, for instance, progress towards meeting the Millennium Development Goals (MDGs)). Since 1992, there has been a growing interest in comparing cities' ecological footprints (Rees 1992) and, more recently, in comparing cities' contributions to anthropogenic greenhouse gas emissions (Dodman 2009). There are also many attempts to compare nations in regard to relationships between urban change and economic change.

The temptation to undertake such comparisons is much magnified by the ease with which large urban population datasets can be acquired. For instance, it is very straightforward to access and use the datasets showing each nation's urban population and level of urbanization, and each major city's population from 1950 to 2005 with projections to 2030 and beyond. Almost everyone who writes about urban issues in Africa, Asia and Latin America draws directly or indirectly on the urban and rural population statistics produced by the United Nations Population Division - usually from the World Urbanization Prospects reports that they have published every two to three years since 1975. Each successive report incorporates the new census data that have become available since the previous report. Most of these reports (and all those published in the last 15 years) contain details of each nation's urban definition (which shows how much these vary) and of the censuses (often limited in number) used for the figures for each nation and for each city. All these reports also give cautions to the reader with regard to comparing urban population statistics between nations because of the different official criteria for defining urban centres or setting city boundaries. These should serve as a caution to those who use the statistics, but they are almost always ignored.

Some of these urban statistics are also included in World Development Indicators Online. From here, it is easy to download urban and rural population statistics for all the world's countries, along with data for these same countries for several hundred other indicators. So, it is easy to compare, for instance, how nations' urbanization levels vary with economic or labour force characteristics, how well the urban and rural populations of every country are served with water and sanitation, or what proportion of these populations are 'poor'. Similarly, one can compare urban primacy levels between nations, which serve as the basis for discussing what social, economic or political factors account for high levels of primacy. However, no account is taken of the differences in how urban populations are defined and the lack of census data for many nations. 


\section{Urban definitions and their impact on urbanization statistics}

The urbanization level for any nation is the proportion of the national population living in urban centres, and so it is influenced by how the national government defines what is an 'urban centre'. For instance, Mexico can be said to be either 74 or 67 per cent urban in 2000, depending on whether urban centres are all settlements with 2,500 or more inhabitants or all settlements with 15,000 or more inhabitants (Garza 2002). China's level of urbanization in 1999 could have been 24 per cent, 31 per cent or 73 per cent, depending on which of three official definitions of urban populations was used (Liu et al. 2003; Zhang 2004). India appears to be a predominantly rural nation, but most of India's rural population lives in settlements with between 500 and 5,000 inhabitants, which are considered as villages and therefore classified as rural; many more live in settlements with more than 5,000 inhabitants, which are still classified as rural (Visaria 1997). If these were classified as 'urban' (as they would be by some national urban definitions), India would suddenly have a predominantly urban population.

In virtually all nations, official definitions ensure that the urban population includes all settlements with 20,000 or more inhabitants, but governments differ regarding what smaller settlements they include as urban centres - from those that include as urban all settlements with a few hundred inhabitants, to those that include only settlements with 20,000 or more inhabitants. This limits the accuracy of international comparisons of urbanization levels because most nations have a large part of their populations living in settlements with between a few hundred and 20,000 inhabitants. For instance, in 1996, 18 per cent of Egypt's population lived in settlements with between 10,000 and 20,000 inhabitants that had many urban characteristics, including significant non-agricultural economies and occupational structures. These were not classified as urban areas although they would have been in most other nations. If they were considered urban, this would mean that Egypt was much more urbanized, causing major changes to urban growth rates (Denis and Bayat 2002). ${ }^{1}$ In Pakistan, in 1998, a considerable proportion of the rural population lived in over a thousand settlements with more than 5,000 inhabitants. However, these would have been counted as urban in the 1972 census - and Pakistan's level of urbanization in 1998 would have been much higher had these been included (Hasan 2006). In Mauritius, in the 2000 census, around a quarter of the population lived in settlements with between 5,000 and 20,000 inhabitants. These settlements included various district capitals that were not classified as urban areas. ${ }^{2}$ If they had been classified as urban, the Mauritian population would have been more than two thirds urban in 2000, rather than less than half urban.

Thus, the scale of the world's urban population is strongly influenced by the urban criteria used within the largest population nations. If the Indian or Chinese government chose to change the urban criteria in their censuses, this could increase or decrease the world's level of urbanization by several percentage points - and there are good reasons for thinking that the current criteria used in China and India considerably understate the size of the urban population. Revisions, for instance, by the Nigerian or Brazilian census

\footnotetext{
1 Another indication that Egypt's urban definition understates its urban population is the fact that, by 1996, two thirds of the labour force worked in industry and services although officially only 43 per cent of the population lived in urban areas.

2 http://www.clgf.org.uk/2005updates/Mauritius.pdf; http://www.citypopulation.de/
} 
authorities could significantly alter the level of urbanization in Africa or South America. In some nations, revisions in their urban definitions are responsible for part of the changes in their urban growth rates and levels of urbanization. Thus, the world's level of urbanization is best understood not as a precise figure (50 per cent in 2008) but as being between 45 and 55 per cent, depending on the criteria used to define urban areas. It might be that the much-discussed transition to more than half the world's population living in urban areas actually took place some years ago, with its recognition delayed by various governments deliberately understating their urban populations by classifying most small urban centres as rural.

\section{City boundaries}

There are comparable problems with comparisons between cities for their populations or population growth rates when statistics for one city are for its central area (excluding most or all suburbs, and much smaller than the built-up area) and for another are for an extended metropolitan area. City boundaries are not set according to universally agreed criteria but according to local and national criteria, and these differ from nation to nation. In addition, most large cities have at least three different figures for their populations. These figures depend on whether it is the city, the metropolitan area or a wider planning (or administrative) region that is being considered, or whether the city population includes the inhabitants of nearby settlements with a high proportion of daily commuters. The current population of most of the world's largest urban areas can vary by many million inhabitants, depending on which boundaries are used.

In 2000, the population of New York City was 8 million; for the New York metropolitan area, the figure was 9.3 million; for the New York-Northern New JerseyLong Island consolidated metropolitan statistical area, 21.2 million (US Census Bureau online): all these figures are valid population statistics for 'New York'. In 2000, Manila could be said to have 1.6 million inhabitants (the population of the city) or 9.9 million (the population of the national capital region). The populations of Bangkok, Beijing, Cairo, Dhaka, Jakarta, London, Mexico City, and Mumbai in 2000 can vary by several million, depending on whether the figure is for the city, the larger 'urban agglomeration', or the city-region (Satterthwaite 2007).

The population figures usually given for the largest Chinese cities are actually for the populations in large local government areas that include significant proportions of people living in rural areas and working in forestry and agriculture. This confusion between local government area and city area explains why the city of Chongqing sometimes appears as the world's largest or second largest city, with a population of 30 million. However, this is the population in the municipality, which covers 82,400 square kilometres (about the size of Austria or the Netherlands and Denmark combined): the city population in 2000 was around 6 million.

There are also many major cities that are within clusters of other cities and smaller centres that are outside their metropolitan boundaries, and these clusters might be considered as single urban agglomerations. China has several urban clusters; for instance, the Pearl River Delta urban cluster (which includes Hong Kong, Guangzhou, and Shenzhen), if considered as a single metropolitan area, would be among the world's 
largest cities (Chu 1996; Lo and Yeung 1996). Germany has many clusters; this explains the many different ways in which its large city populations are classified: the Rhine-Ruhr mega-city region had 11.7 million inhabitants in 2000 and included Essen, Dusseldorf, Cologne, and Bonn (Knapp et al. 2006). Mexico City can be considered at the core of a Central Mexico megalopolis with some 25 million inhabitants (Garza 2002). Some of these clusters of cities cross national boundaries; for example, TijuanaSan Diego in Mexico and the USA; and Singapore-Johore-Riau in Malaysia, Singapore, and Indonesia (Macleod and McGee 1996).

Some cities have boundaries that greatly understate their real populations because they do not include large, dense settlements that have developed outside the official city boundaries. For instance, the population of Colombo in Sri Lanka is often given as around 642,000, but this was the population in 2001 in 'Colombo municipal council'; the urban agglomeration of which this municipal council is at the centre has a much larger population (and Colombo District's urban population was 1.2 million in 2001). ${ }^{3}$

Different boundaries also mean different population growth rates: for example, London, Los Angeles, Tokyo, Buenos Aires, Mexico City, and many other cities, can correctly be stated as having had declining or expanding populations in recent decades, depending on which boundaries are used. ${ }^{4}$ In addition, large increases in a city's population between two censuses are often partly due to an expansion of boundaries that suddenly incorporates many settlements not included as part of the city in the previous census. For instance, this in part explains the rapid growth in Dhaka and some other cities in Bangladesh during the 1980s and early 1990s. In South Africa, some of the large increase in the urban population shown by the 1996 census was due to the inclusion in 1996 of the African urban population living in the 'independent' states created by the apartheid regime, which population had been excluded from censuses in 1980 and 1991 (Crankshaw and Parnell 2002). Statistics used to judge the environmental performance of large cities - as in, say, their freshwater consumption, ecological footprint or greenhouse gas emissions per person - are also greatly influenced by whether the boundary is for the central city, the built-up area or a larger metropolitan region.

\section{Lack of census data}

Accurate statistics for a nation's urban population, or for the population in different urban centres, depend on accurate censuses. ${ }^{5}$ However, in most nations, censuses are taken only every ten years and, in many nations, no census data are available for the last 15 years. When no census data are available, the United Nations Population Division relies on estimates and projections - both for the urban and rural populations of nations

3 These are drawn from official statistics; see www.statistics.gov.lk/census2001/population/district/t002a.htm

4 For a discussion of the different population growth rates of major Asian cities, depending on which boundaries are used, see Jones (2004); other chapters in this volume also discuss this for other nations and regions.

5 There might be some exceptions to this for certain high-income nations, drawn from alternative official information sources. 
(and hence their level of urbanization and the rate at which this is changing), and for the populations of major cities. For many nations, all their urban and city population statistics for 2000 or 2005 or 2010 are based on projections made from data from censuses held 10-20 years ago.

Even in the latest United Nations urban statistical compendium, published in 2008, there is no census data since 1993 for over 30 nations; for more than 10 countries, there is no census data since 1981. Many nations have had only one, two, or three censuses since the late 1940s. So, for these nations, most of their urban statistics are based on projecting census data available for only one, two or three dates backwards and forwards in order to obtain the coverage from 1950 to the present (sometimes assisted by government estimates, the accuracy of which is in doubt).

The lack of recent census data is particularly notable in sub-Saharan Africa - in part, because censuses are seen as expensive, and international donors have been reluctant to support them. This means, however, that urban population statistics for many subSaharan African nations for 2000 or 2005 are based on projections from census data, with the most recent census being in the 1980s or early 1990s. For many such nations, urban trends might have changed dramatically since the 1980s, as the economic, political, and demographic factors underpinning urban population growth or rural-urban migration changed. However, this will not be apparent in their urban population statistics, since these are based on projections from urban trends in earlier decades.

\section{The generation of myths}

It is rare to find international analyses of urban change and economic change that recognize the limitations in the urban data, especially the lack of censuses and the limits to the comparability of many urban statistics.

\subsection{Is Africa well on the way to European levels of urbanization?}

The World Bank and various other commentators have claimed that sub-Saharan Africa was unusual because it urbanized rapidly without economic growth during the 1990s (World Bank 1999; Fay and Opal 2000). However, this claim was not based on any census data for urban populations for 2000 but, rather, on figures derived from projections from urban trends in the 1970s and 1980s. No reliable urban population data were available for 2000, when the World Bank published this claim. Even today, there are no reliable urban population data for many nations for 2000. There are also indications that much of sub-Saharan Africa is less urbanized than the projections suggested and that increases in levels of urbanization are slow or stagnating in many nations in the region (Potts 2006, 2009). In addition, the nations that had the largest increase in their level of urbanization are generally those with the best economic performance (therefore, sub-Saharan Africa is not urbanizing rapidly without economic growth).

Africa is the fastest urbanizing continent in the world - around twice as fast as Latin America and Asia. In 25 years half the entire population will 
live in cities. Africa is well on the way to European levels of urbanization - but without the economic base to sustain it (Commission for Africa 2005: 50).

This quote from the 2005 Commission for Africa report is one among many possible examples of claims that Africa is urbanizing far more rapidly than anywhere else. The report, as many others, also claims that Africa has urbanized at rates that are historically unprecedented. In the above quote, there are at least two major errors and one very dubious prediction. If Africa is the most rapidly urbanizing continent in the world around twice as fast as Latin America and Asia - this implies that the rate of increase in Africa's level of urbanization is twice that of Asia and Latin America. This is not the case: according to the most recent UN dataset for the last decade for which census data are available for most nations (the 1990s), Asia's rate of increase in its level of urbanization was more rapid than that of Africa. Latin America had a much lower rate of increase - but this is hardly surprising as Latin America already had more than three quarters of its population in urban areas.

Perhaps the Commission for Africa report meant that Africa's urban population growth rate, rather the rate of increase in the level of urbanization, was twice that of Latin America and Asia; however, this is also not the case. Africa is certainly not 'well on the way to European levels of urbanization': the most recent UN statistics suggest that 36 per cent of Africa's population lived in urban areas in 2000 compared with 71 per cent for Europe. With regard to whether Africa has urbanized at rates that are historically unprecedented, this is unlikely. For trends over several decades, available data do not show this; for instance, the rates of increase in the levels of urbanization in Asia and in Africa are fairly similar between 1950 and 2000 (although Africa had the faster rate for the first half of this period, Asia having the faster rate for the second half). Perhaps certain African nations urbanized at rates that were unprecedented for particular decades. However, if this were the case, it was largely because they were underurbanized due to the colonial political controls on urban growth and on the rights of Africans to live and work in urban areas. Rapid increases in urbanization levels resulted when these controls were weakened or removed. For the period 1980 to 2000, UN statistics suggest that several African nations had among the world's smallest increases in their levels of urbanization (including Zambia and Egypt, which are reported to have de-urbanized). Potts (2009) points to a number of nations in sub-Saharan Africa with very slow or no increase in their level of urbanization for the most recent inter-census period. However, as noted above, some caution is needed in making generalizations for sub-Saharan Africa as no recent census data are available for many nations; also, for some of these nations, their small increase in level of urbanization (and, for Egypt, deurbanization) could be the result of urban definitions excluding smaller urban centres, many of which have rapidly growing populations.

To support the claim that Africa has urbanized at rates that were 'unprecedented' would require some investigation of other nations that had periods of rapid urbanization - for instance, China from around 1980 to the present, many Latin American nations during periods of rapid industrialization and economic success (some of which predate 1950), or Japan for the decade or two after it industrialized so rapidly. During the 1970s, it was common to see inaccurate assertions that Latin America was the region with 
unprecedented rates of urbanization. Perhaps now we are moving to an era where these inaccurate assertions will be applied to Asia. ${ }^{6}$

\subsection{Is urban growth in Africa, Asia, and Latin America explosive, unprecedented and out of control?}

For over 30 years, it has been common to see statements about the 'explosive growth' of cities or the 'urban explosion' in Africa, Asia, and Latin America, often with comments that it is 'out of control'. However, there is a strong economic logic with regard to where rapid urbanization has taken place and where large cities have developed. The increasingly urbanized population has been driven by the growing concentration of new investment and employment opportunities in urban areas. Within most nations, the main driver of urban change in recent decades is best summarized as the geography of where private enterprises choose to concentrate (or to avoid). Obviously, many other factors also influence urban change - for instance, the competence and accountability of city and municipal governments, the structure of national governments (especially the division of responsibilities, funding and fund-raising powers between different levels of government), and (often rapidly changing) demographic structures. Political change certainly shaped urban systems and trends for most nations in Africa and Asia, especially in the periods immediately prior to and after achieving political independence. In recent decades, however, economic change seems to be the dominant driver of urbanization in most nations, as shown by:

- The high concentration of urban population and largest cities in the world's largest economies;

- The strong association between a nation's per capita income and its level of urbanization;

- How increases in levels of urbanization for most low- and middle-income nations over the last 50 years track increases in the proportion of GDP generated by industry and services, and the proportion of the labour force working in these sectors (Satterthwaite 2007);

- The evidence that it is generally those nations with the most rapid economic growth that have urbanized most, and those with the poorest economic performance that have urbanized least.

In the period from 1950 to 2000, many low-income nations, including some in Africa, had less absolute increase in their urbanization levels than the United States and Switzerland - although the rate of increase in their level of urbanization was generally much higher, largely because they began from such a low base. Even with aggregate figures, the increase in levels of urbanization for Africa (or sub-Saharan Africa) is not unprecedented. Africa's level of urbanization increased from 15 to 36 per cent between 1950 and 2000; the corresponding increase for sub-Saharan Africa was from 11 to 33 per cent. For Europe, this figure rose from 51 to 71 per cent, and in Eastern Europe from

6 The Deputy Director General of the Asian Development Bank recently stated that 'The rate of urbanization that Asia is experiencing is a phenomenon that is unprecedented in human history': http://www.adb.org/media/Articles/2007/11618-asian-urban-crisis-solutions/ 
40 to 68 per cent. There are also many historical precedents of what are, today, highincome nations with larger increases in their levels of urbanization over short periods than most of those taking place in recent decades in low- and middle-income nations. The change in the level of urbanization in low- and middle-income nations between 1950 and 1975 was comparable to that in Europe and North America between 1875 and 1900 (Graumann 1977; Preston 1979). The rates of net rural to urban migration required to achieve these increases might have been greater in Europe and North America in the late nineteenth century than in low- and middle-income nations from 1950 to 1975 because the rates of natural increase in rural areas were probably higher than those in urban areas at that time (Davis 1973).

\subsection{Do cities in low- and middle-income nations have unprecedented population growth rates?}

Most of the world's fastest-growing cities are in low- and middle-income nations, but there are important exceptions; for instance, Las Vegas, Phoenix-Mesa, and Orlando in the USA were among the world's most rapidly growing large cities for the period 19502000. In addition, the population growth rates for rapidly growing cities in low- and middle-income nations in recent decades are rarely unprecedented, as is shown in Table 1. In Table 1 cities are grouped so that they have broadly comparable population sizes at the beginning of the period, except in the fourth grouping. In the fourth group, when viewing population growth over the twentieth century, the growth of Tokyo, Seoul, and Los Angeles (all in high-income nations) is comparable to that of Dhaka, Karachi, and Kolkata (previously Calcutta), three cities often held up as particularly fast growing cities, although for Kolkata population growth rate has dropped greatly in recent decades. The population of Los Angeles was around one tenth that of Kolkata in 1900, yet in 2000, it had about the same number of people in its metropolitan area. Dhaka is certainly one of the world's fastest-growing large cities over the last few decades, although Los Angeles and Dhaka had populations of comparable size in 1900 and in 2000 .

If there were a complete record of population growth rates for all major cities by decade over the last 200 years, it is likely that, during one or more decade since 1950, many of the most rapid population growth rates would have been in cities in low- and middleincome nations. Many would be capitals of sub-Saharan African nations, although, as previously noted, this in part would be as apartheid-like controls on people's movement were removed. But few, if any, would be 'unprecedented': for instance, in comparison with many Southern US cities that have grown so rapidly since 1900 (including some in Table 1); or Chicago or Pittsburgh in the second half of the nineteenth century; or Vancouver, Detroit, and some Australian cities for particular decades during the twentieth century. This point has importance because 'unprecedented' urban growth is so often given as a reason for the very severe urban problems facing most low- and many middle-income nations. If their urban growth is not unprecedented, the reasons for these problems must be reconsidered. 
Table 1: Comparisons of cities' population growth rates over 50- and 100- year periods

\begin{tabular}{|c|c|c|c|c|c|c|c|}
\hline \multirow[b]{2}{*}{ City } & \multicolumn{4}{|c|}{ Population } & \multirow[b]{2}{*}{$\begin{array}{l}\text { Gap } \\
\text { (yrs) }\end{array}$} & \multirow{2}{*}{$\begin{array}{c}\text { Annual } \\
\text { avg. } \\
\text { growth rate }\end{array}$} & \multirow{2}{*}{$\begin{array}{l}\text { Avg. increment } \\
\text { in population, } \\
\text { per yr ('000) }\end{array}$} \\
\hline & Year & ('000) & Year & ('000) & & & \\
\hline Tokyo & 1874 & 596 & 1925 & 5,300 & 51 & 4.4 & 92 \\
\hline New York & 1850 & 516 & 1900 & 4,300 & 50 & 4.3 & 76 \\
\hline Bangalore & 1950 & 746 & 2000 & 5,567 & 50 & 4.1 & 96 \\
\hline Atlanta & 1950 & 513 & 2000 & 3,542 & 50 & 3.9 & 61 \\
\hline Addis Ababa & 1950 & 392 & 2000 & 2,493 & 50 & 3.8 & 42 \\
\hline Los Angeles & 1900 & 102 & 1950 & 4,046 & 50 & 7.6 & 79 \\
\hline Nairobi & 1950 & 137 & 2000 & 2,233 & 50 & 5.7 & 42 \\
\hline Athens & 1900 & 129 & 1950 & 1,783 & 50 & 5.4 & 33 \\
\hline Phoenix-Mesa & 1950 & 221 & 2000 & 2,934 & 50 & 5.3 & 54 \\
\hline Chicago & 1850 & 30 & 1900 & 1,717 & 50 & 8.4 & 34 \\
\hline Abidjan & 1950 & 65 & 2000 & 3,032 & 50 & 8.0 & 59 \\
\hline Las Vegas & 1950 & 35 & 2000 & 1,335 & 50 & 7.6 & 26 \\
\hline Dar es Salaam & 1950 & 67 & 2000 & 2,116 & 50 & 7.1 & 41 \\
\hline Ouagadougou & 1950 & 33 & 2000 & 828 & 50 & 6.7 & 16 \\
\hline Dallas-Fort Worth & 1900 & 43 & 1950 & 866 & 50 & 6.2 & 16 \\
\hline Orlando & 1950 & 75 & 2000 & 1,165 & 50 & 5.6 & 22 \\
\hline Douala & 1950 & 95 & 2000 & 1,432 & 50 & 5.6 & 27 \\
\hline Bamako & 1950 & 89 & 2000 & 1,110 & 50 & 5.2 & 20 \\
\hline Miami & 1900 & 2 & 2000 & 4,946 & 100 & 8.1 & 49 \\
\hline $\begin{array}{l}\text { Los Angeles- } \\
\text { Long Beach-Santa Ana }\end{array}$ & 1900 & 102 & 2000 & 11,814 & 100 & 4.9 & 117 \\
\hline Dhaka & 1900 & 90 & 2000 & 10,285 & 100 & 4.9 & 102 \\
\hline Karachi & 1900 & 136 & 2000 & 10,019 & 100 & 4.4 & 99 \\
\hline Soul (Seoul) & 1900 & 201 & 2000 & 9,917 & 100 & 4.0 & 97 \\
\hline Tokyo & 1900 & $\begin{array}{r}1,49 \\
7\end{array}$ & 2000 & 34,450 & 100 & 3.2 & 330 \\
\hline Kolkata (Calcutta) & 1900 & $\begin{array}{r}1,08 \\
5\end{array}$ & 2000 & 13,058 & 100 & 2.5 & 120 \\
\hline
\end{tabular}


Perhaps one important shift that has taken place is that from major cities being concentrated in the world's most prosperous economies to major cities concentrated in the world's largest economies. Historically, perhaps it has tended to be nations with the highest per capita incomes that have had the largest cities. Now, it is more common for large cities to be in the largest economies, which include large population nations that do not have high average per capita incomes.

\subsection{Primacy and urban bias}

There is a long history of researchers, politicians, and civil servants making normative judgements about urban areas or particular cities having too many people or too much public investment, or of urban populations being privileged over rural populations in some other way by the policies or expenditures of governments and international agencies. Part of this can be seen in discussions of 'over-urbanization', 'premature' urbanization, and urban primacy, and part in discussions of urban bias. There are certainly vigorous debates on these issues - to the point where some claim that urban bias has been a major reason for the scale and depth of poverty worldwide, while others claim that the economic performance of many low-income nations has been greatly hampered by the lack of attention by governments and international agencies to efficient, well-governed, 'investment-attracting' cities and urban systems. ${ }^{7}$

One manifestation of urban bias would be a high proportion of the population living in urban areas relative to the nation's per capita income. Another manifestation of urban bias (or, perhaps more accurately, 'largest-city' bias) might be a high proportion of a nation's urban population in its largest city (urban primacy). But do the data exist to allow such judgements? First, there are uncertainties in the accuracy of the basic data about many nations' levels of urbanization because of a lack of census data for the last 20 years. For the many nations with three or fewer censuses since 1950 (including some with none or only one), this seems a rather limited basis for analysing how rapidly they urbanized over five or six decades. Second, there are differences in the criteria used by governments to define urban populations, which, as already discussed, greatly limit the validity of international comparisons. If a nation's level of urbanization can increase or decrease by as much as 10-20 per cent, depending on what criteria are chosen to define urban populations, this greatly limits the validity of international comparisons.

Because primacy is generally measured by calculating the proportion of a nation's urban population in its largest city, the validity of international comparisons depends on nations having comparable definitions for their urban populations (which is not the case), and similar ways of defining the physical boundaries of the largest city (which is also not the case). In many nations, the level of primacy can depend on which boundary is chosen for the largest city. As previously noted, large cities or metropolitan areas often have two, three or four different populations, depending on which boundary is chosen. Colombo's primacy, for example, is much influenced by which boundary is used for Colombo (that is, did it have around 640,000 or 1.1 million inhabitants around 2000) and which urban definition is used for Sri Lanka (was Sri Lanka 15 per cent or 48 per cent urban in 2005?) (Indrasiri 2006).

7 See, for instance, World Bank (2008). 
Perhaps the literature on primacy has exaggerated the extent of primacy by using figures for primate city populations that were projections that, when census data became available, proved to be too high. To give just one example, consider the paper by Alberto Ades and Edward Glaeser published in 1995, which seeks to explain the apparently high concentration of nations' urban populations in a single city (Ades and Glaeser 1995). This is an influential paper and one that is widely quoted. Many of the city population figures used in this paper are estimates in the absence of any census data, or projections from data from censuses held many years previously. When census data became available to provide a more reliable base for population figures, many cities included in the Ades and Glaeser analysis had populations that were much smaller than the figures that had been used. This analysis also took no account of the differences in the criteria used by nations to define their urban population, even though this obviously influences any measure of primacy when the population of each nation's 'largest city', or a set of the largest cities, is divided by the urban population. It also took no account of the different criteria used to set the boundaries within which city populations are measured. The validity of the data used in the Ades and Glaeser paper on the political structure of nations could also be questioned; this is one among many papers that have sought to analyse associations between urban structures and political structures for a wide range of low- and middle-income nations. The paper claims that there is a robust causality between dictatorships and urban concentration. This is puzzling, in that there are so many examples within the last 60 years of non-democratic governments strongly controlling people's movement to urban areas, including the largest cities - and including many of the colonial regimes in Africa. There are also the examples of non-democratic governments that strongly controlled rural to urban migration and limited urban concentration - including China for the 1960s and 1970s, and South Africa until the apartheid laws were no longer applied. There is also the issue that any nation's largest city and urban system has within it the influence of a long history of political (and economic and demographic) change, and many nations that would have been classified as having dictatorial political structures in the late 1970s or early 1980s also had long periods of democratic governments prior to this. For instance, Chile, Argentina, and Uruguay always figure prominently among the most primate-city dominated nations. However, this cannot be ascribed to the non-democratic governments they had for parts of the 1970s and 1980s, because each of these countries had long periods of democratic government before this. We need far more detailed national analyses of urban change that discuss the underlying economic, political, social, and demographic changes (Bryceson and Potts 2006; Hasan 2006) before we seek generalizations that can be applied to regions or to all low- and middle-income nations.

\subsection{Data limitations distorting urban policies}

This paper has concentrated on the limitations in the data on urban and city populations. There are many other areas where the absence of basic data means the validity of urban statistics can be questioned. For instance, most of the urban poverty statistics for Africa and Asia are derived from poverty lines set with no data on the actual cost of non-food necessities and with very inadequate allowances for non-food expenditures, because of which they understate both the extent and the depth of urban poverty (Satterthwaite 2004). The lack of accurate data also helps explain some magnificently inaccurate figures given for the extent of urban poverty. For example, a paper published in 2003 
suggested that there was virtually no urban poverty in many sub-Saharan African nations (Sahn and Stifel 2003). The application of the US\$1 a day poverty line to urban populations also produces nonsensical statistics in cities or urban populations where the cost of non-food necessities is high. This is both within successful cities and in urban centres where urban poor groups pay high prices for schools, health care, transport and access to water and sanitation because of the inadequacies in public provision, and high prices for housing because of constraints on land supplies for housing. The use of this US $\$ 1$ a day poverty line is worrying, in that this is being used as one of the main indicators to assess progress in meeting the MDGs. Applying the US\$1 a day poverty line means that, by 2002, there was apparently virtually no urban poverty in China, Eastern Europe, Central Asia, the Middle East, and North Africa (Ravallion et al. 2007). ${ }^{8}$ The deficiencies in the official UN statistics on provision for water and sanitation in urban areas has been documented and discussed elsewhere (UN-HABITAT 2003); the problem is mainly in misinterpretation by those using the statistics. This means that the proportion of the urban population with good quality or 'safe and sufficient' provision for water and sanitation is greatly overstated. Official UN statistics cannot be used to monitor MDG progress on provision for water because they do not measure who has 'access to safe water' (UN-HABITAT 2003).

Another factor is the paucity of data on urban populations for key social or health issues. Most available data are drawn from national sample surveys (for instance, the demographic and health surveys) that have sample sizes too small to provide data for individual urban centres (except, perhaps, for the largest city) or to allow much disaggregation. This means that there is little or no data on, say, infant, child, and maternal mortality rates among low-income urban populations. There is also the issue of how little data these surveys collect on housing and living conditions. One also wonders whether the data gatherers for the national surveys actually gather data from those living in informal settlements, either because there is no map or no data on populations in these settlements, or because those collecting the data are frightened to enter these settlements. However, informal settlements house a large part of the urban population in most low- and middle-income nations.

In addition, the validity of discussing conditions and trends for the urban population of any nation has to be questioned, given the diversity of urban centres within most nations. For instance, there are very few studies of conditions in urban centres with less than 50,000 inhabitants yet many nations have a fifth or more of their national population living in these (Satterthwaite 2006). There is little in common between small market towns in areas with stagnant economies in (say) Argentina, China and India and Buenos Aires, Shanghai and Delhi.

There is an important new area where lack of data is driving inappropriate policy responses. This is the lack of data on greenhouse gas emissions for urban centres in Africa and Asia. This has led to assumptions that these urban centres have high levels of greenhouse gas emissions, which then underpin more attention by international agencies to greenhouse gas emission reduction (mitigation) rather than to protecting these urban

\footnotetext{
8 Applying this US\$1 a day poverty line, they suggest that less than 1 per cent of the urban population of China, Eastern Europe, Central Asia, North Africa and the Middle East are poor. This paper seems to regard these measures as valid. See Solinger (2006) for a discussion of the real scale and depth of urban poverty in China.
} 
centres' populations from the often very serious risks they face from climate change (adaptation). More generally, there is also the issue of cities being blamed for global warming - for instance, through the widely used but inaccurate statistic that cities emit 75 to 80 per cent of all anthropogenic greenhouse gas emissions, when they probably emit substantially less than half of all such emissions (Satterthwaite 2008).

Our understanding of urbanization in Europe over the last 250 years is driven by a relatively weak and incomplete set of statistics on levels of urbanization and city populations; it is, though, underpinned by a rich information base on social, economic, political and demographic history. By contrast, today, we have what appears to be a complete set of statistics for all nations and territories for their level of urbanization, and for the population of capitals and large cities from 1950 to the present; however, these are so often interpreted with no knowledge of the social, economic, political and demographic underpinnings of urban change. The world's largest cities, or its fastest or slowest growing large cities, or the nations with the most rapid urbanization can be listed and compared, independent of any knowledge of these cities or nations, or of the limitations in the data about them. This needs to change.

\section{References}

Ades, A.F., and Glaeser, E.L. (1995). 'Trade and Circuses: Explaining Urban Giants'. Quarterly Journal of Economics, 110(1): 195-227.

Bryceson, D.F., and Potts, D. (eds). (2006). African Urban Economies: Viability, Vitality or Vitiation?. Basingstoke: Palgrave Macmillan.

Chu, D.K.Y. (1996). 'The Hong Kong-Zhujiang Delta and the World City System'. In Lo Fu-Chen and Yue-Man Yeung (eds), Emerging World Cities in Pacific Asia. Tokyo: United Nations University Press, 465-97.

Commission for Africa (2005). Our Common Interest: Report of the Commission for Africa. London: Commission for Africa.

Crankshaw, O., and Parnell, S. (2002). 'Urban Change in South Africa'. Urban Change Working Paper 4. London: IIED.

Chandler, T. (1987). Four Thousand Years of Urban Growth: An Historical Census. Lampeter: Edwin Mellen Press.

Davis, K. (1973). 'Cities and Mortality'. International Population Conference, International Union for the Scientific Study of Population (IUSSP), 3: 259-82.

Denis, E. and Bayat, A. (2002). 'Egypt; Twenty Years of Urban Transformations'. Urban Change Working Paper 5. London: IIED.

Dodman, D. (2009). 'Blaming Cities for Climate Change? An Analysis of Urban Greenhouse Gas Emissions Inventories’. Environment and Urbanization 21(1): 185201.

Fay, M., and Opal, C. (2000). Urbanization without Growth: A Not So Uncommon Phenomenon. Washington, DC: World Bank. 
Garza, G. (2002). 'Urbanization of Mexico during the Twentieth Century'. Urban Change Working Paper 7. London: IIED.

Graumann, J.V. (1977). 'Orders of Magnitude of the World's Urban and Rural Population in History’. United Nations Population Bulletin 8. New York: UN: 1633.

Hasan, A. (2006). The Scale and Causes of Urban Change in Pakistan. Karachi: Ushba Publishing International.

Indrasiri, L.H. (2006). Urbanization and Urban Redefinition - Sri Lanka 2005. Urban Development Authority. Available at: www.uda.lk/reports/Urbanization\%20 and\%20 Urban\%20Redefinition\%202005.pdf

Jones, G.W. (2004). 'Urbanization Trends in Asia: The Conceptual and Definitional Challenges'. In T. Champion and G. Hugo (eds), New Forms of Urbanization: Beyond the Urban-Rural Dichotomy. Aldershot: Ashgate, 113-50.

Knapp, W., Scherhag, D., and Schmitt, P. (2006). 'RhineRuhr: Policentricity at its Best'. In P. Hall and K. Pain (eds), The Polycentric Metropolis: Learning from Mega-City Regions in Europe. London: Earthscan, 154-62.

Liu, S., Li, X., and Zhang, M. (2003). Scenario Analysis on Urbanization and RuralUrban Migration in China. Vienna: International Institute for Applied Systems Analysis.

Lo, F.-C., and Yeung,Y.-M. (1996). 'Global Restructuring and Emerging Urban Corridors in Pacific Asia'. In F.-C. Lo and Y.-M. Yeung (eds), Emerging World Cities in Pacific Asia. Tokyo: United Nations University Press, 17-47.

Macleod, S., and McGee, T.G. (1996). 'The Singapore-Johore-Riau Growth Triangle: An Emerging Extended Metropolitan Region'. In F.-C. Lo and Y.-M. Yeung (eds), Emerging World Cities in Pacific Asia. Tokyo: United Nations University Press, 417-64.

Potts, D. (2006). 'Urban Growth and Urban Economies in Eastern and Southern Africa: Trends and Prospects'. In D.F. Bryceson and D. Potts (eds), African Urban Economies: Viability, Vitality or Vitiation? Basingstoke: Palgrave Macmillan, 67-98.

Potts, D. (2009). 'The Slowing of Sub-Saharan Africa's Urbanization: Evidence and Implications for Urban Livelihoods'. Environment and Urbanization, 21(1): 253-9.

Preston, S.H. (1979). 'Urban Growth in Developing Countries: A Demographic Reappraisal’. Population and Development Review, 5(2): 195-215.

Ravallion, M., Chen, S., and Sangraula, P. (2007). 'New Evidence on the Urbanization of Global Poverty’. BW Policy Research Working Paper Series 4199. Washington, DC: World Bank.

Rees, W.E. (1992). 'Ecological Footprints and Appropriated Carrying Capacity'. Environment and Urbanization, 4(2): 121-30.

Sahn, D.E., and Stifel, D.C. (2003). 'Progress Toward the Millennium Development Goals in Africa'. World Development, 31: 23-52. 
Satterthwaite, D. (2004). 'The Under-estimation of Urban Poverty in Low and MiddleIncome Nations'. IIED Working Paper 14 on Poverty Reduction in Urban Areas. London: IIED.

Satterthwaite, D. (2006). 'Outside the Large Cities; the Demographic Importance of Small Urban Centres and Large Villages in Africa, Asia and Latin America'. Human Settlements Discussion Paper; Urban Change-3, London: IIED.

Satterthwaite, D. (2007). 'The Transition to a Predominantly Urban World and its Underpinnings’. Human Settlements Discussion Paper. London: IIED.

Satterthwaite, D. (2008). " “Cities”, Contribution to Global Warming: Notes on the Allocation of Greenhouse Gas Emissions'. Environment and Urbanization, 20(2): 539-549.

Solinger, D. J. (2006). 'The Creation of a New Underclass in China and its Implications'. Environment and Urbanization, 18(1): 177-194.

UN (United Nations) (2008). World Urbanization Prospects: The 2007 Revision. CDROM edn, data in digital form (POP/DB/WUP/Rev.2007). Department of Economic and Social Affairs, Population Division.

UN-HABITAT (2003). Water and Sanitation in the World's Cities: Local Action for Global Goals. London: Earthscan.

US Census Bureau. Available at: www//212.204.253.230/cd/us_agg2.php

Visaria, P. (1997). 'Urbanization in India: An Overview'. In G. Jones and P. Visaria (eds), Urbanization in Large Developing Countries. Oxford: Clarendon Press, 26688.

World Bank (1999). Entering the 21st Century: World Development Report 1999/2000. Oxford and New York: Oxford University Press.

World Bank (2008). World Development Report 2009. New York: World Bank.

Zhang, L. (2004). China's Limited Urbanization under Socialism and Beyond. New York: Nova Science Publishers. 